\title{
Why Commercial Pilots Voluntarily Report Self-Inflicted Incidents
}

\section{A Qualitative Study With Aviation Safety Experts}

\author{
Sebastian Sieberichs@ and Annette Kluge( \\ Work, Organisational \& Business Psychology, Department of Psychology, Ruhr University Bochum, Germany
}

\begin{abstract}
Voluntary incident reports by commercial pilots provide essential data for airline efforts in learning from incidents (LFI). Because LFI is frequently limited by pilots not reporting incidents voluntarily, we interviewed seven commercial aviation safety experts in a focus group to derive factors influencing the voluntary reporting behavior of pilots' self-inflicted incidents. As a result, we derived 36 factors and integrated them into a motivational framework by van den Broeck et al. (2019). Pilots pursue various goals when voluntarily reporting incidents, such as enabling safetyrelated change or organizational learning. This behavior is influenced by personal antecedents, such as shame, and contextual antecedents, such as feedback. Our work expands the understanding of motivational aspects of voluntary incident reporting and discusses practical interrelations.
\end{abstract}

Keywords: learning from incidents, voluntary reporting behavior, self-inflicted incidents, goals, motivation

The International Air Transport Association (IATA) has published a whitepaper pointing out that, "a Safety Management System (SMS) is not sufficient to ensure safety" and identifies the ability of an organization to learn as one of eight drivers to prevent accidents (International Air Transport Association [IATA], 2019, p. 3). For high-reliability organizations (HROs) such as commercial airlines, the ability of learning from incidents (LFI) is an essential element to develop mindfulness for emerging threats and thus to produce fewer accidents than would be statistically expected despite a high hazard potential (Drupsteen et al., 2013; Weick \& Sutcliffe, 2007). In commercial aviation, incidents are usually distinguished according to whether they are related to the operation of the aircraft, to technical conditions, to maintenance and repair of the aircraft, to air navigation services and facilities, or to aerodromes and ground services (European Parliament, 2014, pp. 26-27). For incidents related to the operation of the aircraft, the primary contributing factor continues to be a limited pilot performance (IATA, 2020, p. 45); in this paper we therefore only address pilots' self-inflicted incidents caused by their errors and violations and not, for example, by technical failures.

\section{Incident Reporting in High Reliability Organizations}

LFI means considering incidents - occurrences in which no damage has been caused although there was a potential for it (International Civil Aviation Organization [ICAO],
2019) - fundamentally as an "input to learn from" in order to use and share lessons learned from the incident analysis with the organization members (Drupsteen \& Guldenmund, 2014, p. 83). In their LFI efforts, commercial airlines depend considerably on written incident reports from their pilots. However, studies consistently highlight that underreporting constitutes a major bottleneck in LFI activities (e.g., Drupsteen \& Hasle, 2014; Margaryan et al., 2017; Stemn et al., 2018).

Reasons for underreporting are manifold and include, for example, different facets of fear (e.g., Probst \& Estrada, 2010) or various aspects of the reporting system. Reporting behavior is also influenced by the safety climate within the organization as it comprises, "shared employee perceptions about the relative importance of safe conduct in their occupational behavior" (Curcuruto \& Griffin, 2018; Zohar, 1980 , p. 96). Moreover, incident-reporting behavior is affected by various aspects of safety-related organizational cultural characteristics (Hedlund et al., 2010; Reason, 1998; Stemn et al., 2018): A safety culture guides the safety-related behavior of organization members through implicit processes and underlying assumptions and values related to safety, without being directly accessible to conscious perception (Curcuruto \& Griffin, 2018). Safety culture is closely linked to a learning culture in which errors and the resulting incidents are accepted and seen as an opportunity for learning (Littlejohn et al., 2014). A so-called reporting culture implies that incidents are reported voluntarily and requires a just culture, providing an atmosphere of openness and trust encouraging reporting but 


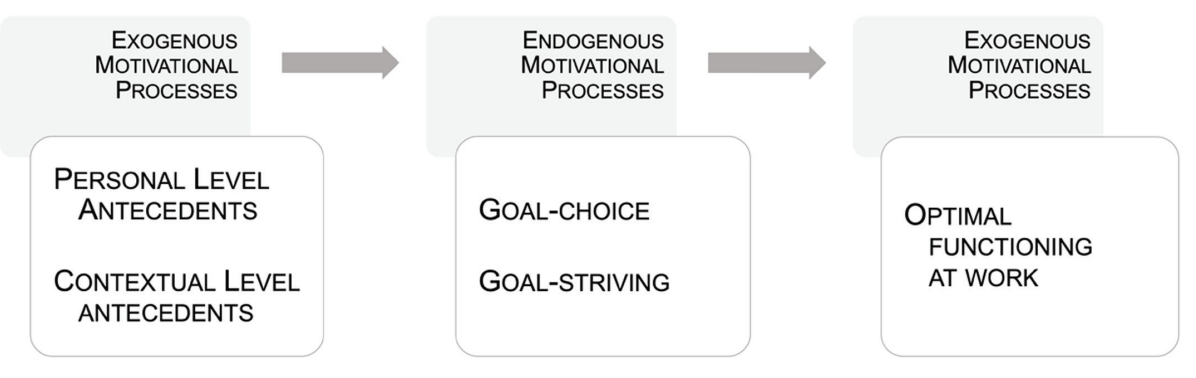

Figure 1. Simplified representation of the heuristic conceptual motivational framework according to van den Broeck et al. (2019). distinguishing between acceptable and unacceptable behavior (Dekker, 2018; Drupsteen \& Guldenmund, 2014; Reason, 2016).

To organize factors that affect reporting behavior, this study will adopt a work motivation perspective using the heuristic conceptual motivational framework in which reporting behavior can be understood in terms of an "optimal functioning at work" (van den Broeck et al., 2019). This framework integrates central perspectives of work motivation and relies on the overall assumption that all behavior at work is goal-directed. Moreover, the model considers how organizational members regulate their behavior and which personal antecedents (e.g., momentary states like fear) and contextual antecedents (e.g., climate) influence the emergence of motivation. An interaction of these socalled exogenous and endogenous motivational processes influences the organizational members' "optimal functioning at work." A simplified illustration of the framework is shown in Figure 1.

Table 1 is intended to provide an overview of various factors that were shown to influence incident reporting of HRO members in empirical studies in recent years; these factors were assigned to the motivational processes according to the motivational framework. In the area of personallevel antecedents, reporting behavior may be constrained, for example, by various facets of fear (e.g., Probst \& Estrada, 2010). In the field of contextual-level antecedents, we find, for example, that commercial airlines can establish a reporting-friendly environment with adequate reporting systems (e.g., Jausan et al., 2017) and different aspects of the organizational culture or climate (e.g., Reason, 2016). Goal-related factors also involve aspects of the incident itself (e.g., Sieberichs \& Kluge, 2018).

\section{Voluntary Incident-Reporting Behavior}

In commercial aviation, legal requirements specify which incidents are mandatory to be reported (Drupsteen \& Wybo, 2015; European Parliament, 2014; ICAO, 2013). However, incidents that might not be captured by legal reporting requirements often include safety-related information about potential hazards to flight safety that are relevant for LFI (Drupsteen \& Wybo, 2015; European
Parliament, 2014; ICAO, 2013); these incidents must be reported voluntarily by the pilots.

Voluntary incident-reporting behavior of organization members can be considered a form of safety citizenship behavior (SCB) and can be located on the dimension initiating safety-related change (Hofmann et al., 2003; Wishart et al., 2019). SCB is based on the concept of reciprocity and can be described from the perspective of social exchange theory as a mutual relationship between two parties (Didla et al., 2009). It describes individual behaviors related to safety, which support the overall safety condition of the workplace and exceed the mere compliance with safety regulations (Curcuruto et al., 2015; Griffin \& Neal, 2000). In particular, members of HROs perceive personal commitment in the sense of SCB as personal responsibility (Curcuruto \& Griffin, 2018). The emergence of SCB can be described by proximal, personal antecedents such as affective engagement and psychological ownership and distal, situational antecedents such as organizational support and the safety climate (Curcuruto \& Griffin, 2018; Parker et al., 2010). In safety literature, SCB is often used interchangeably with the term "safety participation" (Conchie, 2013; Griffin \& Curcuruto, 2016). Especially discretionary forms of safety participation such as voluntary reporting behavior were shown to be influenced by the safety climate of an organization.

\section{Research Gap in Commercial Pilots' Voluntarily Reporting Behavior}

The factors presented in Table 1 were intended to provide an overview of the factors that can affect the incidentreporting behavior of members in HROs.

It is necessary to verify whether these factors also apply to incident-reporting behavior that is explicitly voluntary.

Moreover, only few findings shown in Table 1 are directly derived from studies with commercial pilots (Gilbey et al., 2016; Haslbeck et al., 2015) or commercial pilots are considerably underrepresented in studies conducted within aviation organizations (Jausan et al., 2017). This might be critical, because aspects such as a silence code (cf. Jausan et al., 2017), which prevails primarily in organizations with 
Table 1. Factors influencing overall reporting behavior

\begin{tabular}{|c|c|c|c|}
\hline Level & Factors & Impact & Author \\
\hline Personal-level & Fear of consequences & - & Jausan et al. (2017) \\
\hline \multirow[t]{11}{*}{ antecedents } & Lack of knowledge about how to file a report & - & Jausan et al. (2017) \\
\hline & Trust, general & + & Jausan et al. (2017) \\
\hline & Risk-taking attitudes & - & Nykänen et al. (2019) \\
\hline & Moral disengagement & - & Petitta et al. (2017) \\
\hline & Fear, being blamed & - & Probst \& Estrada (2010) \\
\hline & Fear, lost group's scorecard points & - & Probst \& Estrada (2010) \\
\hline & Fear, unfair performance evaluation & - & Probst \& Estrada (2010) \\
\hline & Belief: "Nothing will be done to fix the problem" & - & Probst \& Estrada (2010) \\
\hline & Shame & - & Stemn et al. (2018); Zabari \& Southern (2018) \\
\hline & Negative attitudes toward safety behavior & - & Sawhney \& Cigularov (2019) \\
\hline & Fear, loss of reputation & - & Zabari \& Southern (2018) \\
\hline Contextual-level & Nonpunitive environment & + & Barach (2000); Jausan et al. (2017); Gilbey et al. (2016) \\
\hline \multirow[t]{13}{*}{ antecedents } & Transformational leadership & + & Chen \& Chen (2014) \\
\hline & Morality leadership & + & Chen \& Chen (2014) \\
\hline & Perceptions that SMS practices are applied & + & Chen \& Chen (2014) \\
\hline & Safety climate & + & Curcuruto \& Griffin (2018) \\
\hline & Safety cultural aspects & + & Dekker (2018); Reason (2016) \\
\hline & Distinct reporting behavior of colleagues & + & Jausan et al. (2017) \\
\hline & Culture of blame & - & Jausan et al. (2017) \\
\hline & Code of silence & - & Jausan et al. (2017) \\
\hline & Reporting system, user-friendly & + & Jausan et al. (2017) \\
\hline & Reporting system, financial priority & + & Jausan et al. (2017) \\
\hline & Reporting system, feedback on a report & + & Jausan et al. (2017) \\
\hline & Reporting system, confidential option & + & Langer (2016); Merry \& Henderson (2017) \\
\hline & "All is well that ends well" mentality & - & van der Schaaf \& Kanse (2004) \\
\hline \multirow[t]{8}{*}{ Goal-related factors } & High workload & - & Jausan et al. (2017) \\
\hline & Positive personal experiences with feedback & + & Jausan et al. (2017) \\
\hline & Issues with the report generation & - & Jausan et al. (2017) \\
\hline & Internal safety locus & + & Nykänen et al. (2019) \\
\hline & Safety self-efficacy & + & Nykänen et al. (2019) \\
\hline & Causes of incident & a & Sieberichs \& Kluge (2018) \\
\hline & Severity of incident, individual evaluation & b & Sieberichs \& Kluge (2018) \\
\hline & Clarity on what constitutes a reportable incident & + & Stemn et al. (2018) \\
\hline
\end{tabular}

Note. Factors influencing overall reporting behavior by elements of the motivational framework listed in alphabetical order of author names; SMS = safety management system; + = a positive influence of the factor on overall reporting behavior; - = a negative influence. 'Incidents caused by pilots' errors or violation less likely to be reported. ' Incidents with low severity are less likely to be reported.

very rigid hierarchical structures like the military (Jausan et al., 2017), may be less likely to be prevalent in commercial airlines due to less rigid hierarchical structures. Therefore, the factors in Table 1 cannot be applied to commercial pilots without prior review.

In addition, many studies do not clearly specify the type of incident to which the reporting behavior applies; however, studies have been able to show that reporting behavior can differ fundamentally according to the type of incident or its causes (Haslbeck et al., 2015; Sieberichs \& Kluge, 2018).

Finally, voluntary reporting behavior, like any type of work behavior, is goal-directed (van den Broeck et al.,
2019). Nevertheless, individual goals of the report authors have been somewhat neglected in the body of research related to incident reporting.

Therefore, our research aims exclusively to improve the understanding of voluntary reporting behavior of commercial pilots' self-inflicted incidents.

Our research question is: Which endogenous and exogenous motivational factors influence the voluntary reporting behavior of commercial pilots' self-inflicted incidents?

This research interest meets the criteria of being a "worthy topic" (Tracy, 2010) because a deeper understanding of commercial pilots' voluntary reporting behavior can help their airlines widen a critical bottleneck of LFI and 
Table 2. Qualification criteria of the experts

\begin{tabular}{|c|c|c|c|c|c|c|c|}
\hline $\begin{array}{l}\text { Expert } \\
\text { Number }\end{array}$ & Sex & $\begin{array}{c}\text { Aircraft } \\
\text { accident } \\
\text { investigator }\end{array}$ & $\begin{array}{l}\text { Several years } \\
\text { of experience in } \\
\text { receiving and processing } \\
\text { written and oral reports }\end{array}$ & $\begin{array}{l}\text { Several years of } \\
\text { experience in conducting } \\
\text { interviews with pilots } \\
\text { on incidents }\end{array}$ & $\begin{array}{c}\text { Knowledge of } \\
\text { organizational LFI and } \\
\text { safety management } \\
\text { processes }\end{array}$ & $\begin{array}{l}\text { Active } \\
\text { commercial } \\
\text { pilot }\end{array}$ & $\begin{array}{c}\text { Trusted pilot } \\
\text { in the } \\
\text { airline }\end{array}$ \\
\hline $1^{1}$ & $F$ & $Y$ & $Y$ & $Y$ & $Y$ & & \\
\hline 2 & $M$ & Y & $Y$ & Y & $Y$ & 0 & Y \\
\hline 3 & $M$ & Y & Y & Y & $Y$ & C & Y \\
\hline $4^{2}$ & $M$ & Y & $Y$ & Y & Y & C & \\
\hline 5 & $M$ & Y & Y & Y & $Y$ & C & \\
\hline 6 & $M$ & Y & Y & Y & $Y$ & C & \\
\hline 7 & $\mathrm{M}$ & $Y$ & $Y$ & $Y$ & $Y$ & 0 & \\
\hline
\end{tabular}

Note. $F=$ female; $M=$ male; $Y$ = yes; $C=$ captain; $O=$ officer. Age was omitted to promote anonymity of the experts; all experts are members of a safety department for more than 10 years. ${ }^{1}$ Responsibility for the processing of all safety-related incident reports of this airline. ${ }^{2}$ Former safety pilot of a German airline. ${ }^{3}$ If no report is available despite conspicuous flight data, these pilots approach the pilots responsible for the incident to find out the background to the incident and the reasons for the absence of the report.

thus improve their ability to learn (Drupsteen \& Hasle, 2014; IATA, 2019).

The aim of this study is to investigate factors that influence the voluntary reporting behavior of commercial pilots' self-inflicted incidents. Although the team in the cockpit consists of two or more pilots, the focus in this research is the reporting behavior of the pilot who caused the incident through their errors or violations and not a potential reporting behavior of its observer.

The research question will be addressed by interviewing experts from the specific social context of the specialized profession of commercial aviation in a focus group design. We consider this methodology to be appropriate, because the expertise and attitudes of the interview participants being persons involved in the LFI process can be regarded as one of the most important prerequisites for LFI (Drupsteen \& Guldenmund, 2014). Previous experience with a comparable procedure is available, for example, from Mitchell et al. (2016).

\section{Method}

\section{Focus Group}

Seven commercial aviation experts were interviewed in an open, semi-structured, qualitative focus group, to make statements in relation to the aforementioned research question about areas of knowledge and reality sections that they know and are aware of. Following a narrow definition, we defined experts to be members of a functional group who, based on their role in the airline, have specific knowledge about receiving and processing safety-related incident reports.

The participants were addressed personally by the authors. The recruitment process took 6 months. Based on a recommendation by Schulz et al. (2012) to recruit between seven and nine participants for a focus group, eight experts were selected, one of whom did not show up for the scheduled interview. Table 2 summarizes the qualification criteria of the participating seven experts.

\section{Moderators}

Two male moderators, who also had the aforementioned expertise, took care of formal management, thematic control, note-taking, summarizing interim results, and discussing ad hoc interpretations. During a 90-min moderator briefing, the interview objectives were defined and strategies for dealing with challenges were deliberated in group discussions. An emphasis was placed on aspects of relational ethics, which includes an "ethical self-consciousness in which researchers are mindful of their character, actions, and consequences upon others" (Tracy \& Hinrichs, 2017, p. 9).

\section{Focus Group Conduct}

A 30-min get-together at a coffee bar was held beforehand to create a relaxing atmosphere. The room used for the interview was selected to be sufficiently sized, air-conditioned, and easy to reach, also by public transport; drinks, coffee, tea, and snacks were available. The seating arrangement is illustrated in Figure 2. The focus group was conducted in German on an afternoon in summer 2019.

A predefined guideline was developed to structure the focus group and converted into a presentation that was displayed on a screen during the interview. The focus group was structured in five phases based on the model for theme-centered interaction (Cohn, 2000) to consider individual, group, and topic-related aspects (Helfferich, 2019; Schulz et al., 2012). The sequence of questions included opening, introductory, transitional, key, and closing questions (Krueger \& Casey, 2014). In formulating the questions, the experts' competencies in terms of 


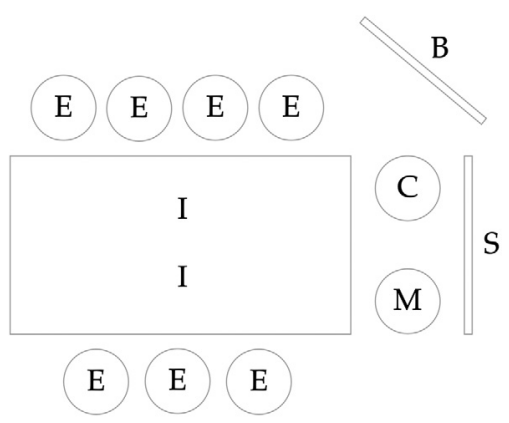

Figure 2. Schematic illustration of the interview setting. $E$ = expert; $\mathrm{M}=$ moderator; $\mathrm{C}=$ co-moderator; $\mathrm{S}=$ screen; $\mathrm{B}=$ board; $\mathrm{I}=$ microphone.

communication and verbalization skills were considered with a view to a conducive discourse culture and attention was paid to general comprehensibility and natural language (Helfferich, 2019; Schulz et al., 2012). The comprehensibility of the interview questions was tested in advance with five randomly selected pilots who were members of the airline's safety department not attending the focus group.

The focus group interview consisted of three phases: In the first phase (welcome and introduction) the research question and the objectives of the interview were presented by the main moderator. A declaration of consent to the collection, processing, and disclosure of personal data derived from the interview was signed by the participants and a data protection declaration on the handling of the data was distributed. The experts were explicitly advised to address even seemingly trivial aspects due to their shared background of experience. The second phase started with an open question about the participants' individual voluntary reporting behavior and their opinion regarding the relevance of voluntary incident reporting for organizational learning to facilitate the introduction from an egocentric self-image (Bühler, 1999). The third phase contained 10 questions designed to derive aspects for answering the research question. We asked, for example, why incidents are reported with different frequencies or why the level of information in incident reports differs. To increase the validity of the findings at the end of this phase, a mind map with bullet points was created by all participants to summarize the main aspects (cf. Schulz et al., 2012). Finally, the participants were asked whether important aspects were neglected, and which aspects were particularly important for them. The focus group ended after $145 \mathrm{~min}$; the participants received a voucher worth 50 Euro afterwards.

For documentation purposes, an audio recording was made, and the main aspects of the discussion were noted by both moderators; nonverbal behavior was not observed or documented.

\section{Transcription}

The audio recording was transcribed into typewritten form by the main moderator and a non-expert person who was not involved in the research process. The final transcript was produced from both versions in which the aspects noted in the moderators' minutes were marked. A transcription guide was set up before starting the transcription. This guide included, for example, instructions to transcribe all statements without filler words, to make them completely anonymous, and to mark longer pauses (cf. Renner \& Jacob, 2020).

\section{Qualitative Content Analysis}

The software MAXQDA (version 2020) was used. MAXQDA is a program for analyzing qualitative data and serves as a computer-assisted qualitative data analysis software. We used a qualitatively oriented, category-driven, content-structuring text analysis according to Mayring (2016). This method was demonstrated to be suitable for the evaluation of group interviews (Mayring, 2020). The complete transcript was defined to be the evaluation unit and was evaluated by the main moderator from beginning to end. A complete statement of a participant was defined to be a coding unit as well as a context unit. This was intended to identify possible code intersections and to simplify the calculation of the interrater agreement.

A mixed deductive-inductive approach was used to develop the categories: The factors influencing reporting behavior (cf. Table 1) were transformed into deductive categories on the basis of theory (Schreier, 2012). A coding guideline was created in which the individual categories were defined and provided with coding rules and anchor examples. These rules were modified in a pilot phase of two processing units in the course of their application to the empirical material and refined in the sense of a circular model with feedback loops (Mayring, 2015). In the final processing unit, the rules were kept constant in the sense of a linear model (Mayring \& Fenzl, 2019).

To code text passages that were not covered by a coding rule but contained relevant text passages for answering the research question, new categories were inductively formed in the course of summarizing paraphrasing and generalizing the text material with increasing reduction, aimed to be semantically as close as possible to the source material. When developing categories, formal criteria of completeness and saturation and content-related criteria of accuracy, exclusivity, and exhaustivity were considered. The inductively developed categories were transferred to the coding guide and provided with coding rules and anchor examples. These rules were modified in a pilot phase of two processing units and kept constant in the final processing unit. After a non-expert person who was not 
Table 3. Overview of deductive categories

\begin{tabular}{|c|c|c|c|}
\hline \multirow[b]{2}{*}{ Category } & \multicolumn{2}{|c|}{ Coding units } & \multirow[b]{2}{*}{ Text example } \\
\hline & $n$ & $\%$ & \\
\hline \multicolumn{4}{|l|}{ Personal-level antecedents } \\
\hline Shame & 15 & 5.07 & And there again it is, the feeling of shame (pos. 149) \\
\hline Fear, disciplinary action & 7 & 2.36 & $\begin{array}{l}\text { Fear, which is partly still rampant, that this could get back to you in } \\
\text { front of your boss (pos. 69) }\end{array}$ \\
\hline Trust, general & 7 & 2.36 & He did not write anything because he had no trust (pos. 233) \\
\hline Risk-taking attitudes & 3 & 1.01 & $\begin{array}{l}\text { Types that we call "fully tattooed," who simply have a completely } \\
\text { different perception, a completely different threshold to rank } \\
\text { something [as] a severe case (pos. 200) }\end{array}$ \\
\hline \multicolumn{4}{|l|}{ Contextual-level antecedents } \\
\hline Reporting system, feedback on a report & 19 & 6.42 & $\begin{array}{l}\text { If we do not give feedback, I think we torpedo the reporting system and } \\
\text { the motivation to write something decreases (pos. 273) }\end{array}$ \\
\hline Reporting system, confidential option & 15 & 5.07 & The big things are only reported to us confidentially (pos. 341) \\
\hline Reporting system, user-friendly & 13 & 4.39 & $\begin{array}{l}\text { You have different reporting media; you can easily use a sheet of paper } \\
\text { (pos. 168) }\end{array}$ \\
\hline Safety cultural aspects & 7 & 2.37 & It was a culture in which it was possible to report (pos. 41) \\
\hline Nonpunitive environment & 4 & 1.35 & The reporting system is based on nonpunitive aspects (pos. 331) \\
\hline Behavior of colleagues & 1 & 0.34 & $\begin{array}{l}\text { Because another pilot is reporting what he should not have reported } \\
\text { (pos. 332) }\end{array}$ \\
\hline \multicolumn{4}{|l|}{ Goal-related factors } \\
\hline Severity of incident, individual evaluation & 32 & 10.81 & $\begin{array}{l}\text { The subjectively perceived risk is probably so low, that it is not worth } \\
\text { writing a report (pos. } 80 \text { ) }\end{array}$ \\
\hline Causes of incident & 20 & 6.76 & I have written reports, but rarely on self-inflicted incidents (pos. 7) \\
\hline Issues with the report generation & 6 & 2.03 & I filed a complete report and suddenly everything was erased (pos. 302) \\
\hline Feedback, prior experience & 3 & 1.01 & $\begin{array}{l}\text { Everyone who filed a report has the experience that the answer was not } \\
\text { satisfactory (pos. 138) }\end{array}$ \\
\hline Workload, overall & 2 & 0.68 & Full duty rosters hinder reporting (pos. 298) \\
\hline Clarity on what constitutes a reportable incident & 1 & 0.34 & $\begin{array}{l}\text { Often, I am insecure, should I write something about this particular } \\
\text { incident (pos. 94) }\end{array}$ \\
\hline
\end{tabular}

Note. Categories that were also addressed as part of the experts' mind map are indicated in bold.

involved in the research process was familiarized with the final coding rules, she applied them to the entire evaluation unit as a second coder. Different coding of the two raters were subsequently discussed during a coding conference and were adjusted for the final evaluation.

All categories including their frequencies were exported and a text sample was selected for each category; code intersections were investigated in a contingency analysis. All text samples were translated into English by one of the moderators and another person with advanced English skills who was not involved in the research process.

The interrater agreement between the evaluating moderator and the second coder was calculated according to Brennan and Prediger (1981) with $\kappa=.87$. Following Landis and Koch (1977), this corresponds to an almost perfect agreement and following Altman (1990) to a very good agreement.

\section{Results}

The categories represent factors that influence the voluntary reporting behavior of pilots' self-inflicted incidents according to commercial aviation safety experts.
Table 3 presents an overview of the deductively applied categories and Table 4 summarizes the inductively developed categories. The categories are presented in different sections according to exogenous and endogenous factors based on the motivational framework (van den Broeck et al., 2019) and are listed in descending order of the frequency of its application in the coding of the transcript. Moreover, the percentage of application of the category across the entire transcript is given. In addition, a text example with its position in the transcript ("pos. x") is provided for each category. The mind map created by the experts at the end contained 12 bullet points that are shown in bold-face print in Tables 3 and 4 .

A total of 155 (52.4\%) coding units were coded with deductive categories: $10.8 \%$ related to individual-level exogenous motivational factors, $19.9 \%$ related to contextual-level exogenous motivational factors, $21.6 \%$ related to endogenous motivational factors.

A total of $141(47.6 \%)$ coding units were coded with inductive categories: $10.8 \%$ related to individual-level exogenous motivational factors, $11.8 \%$ related to contextual-level exogenous motivational factors, $25.0 \%$ related to endogenous motivational factors. 
Table 4. Overview of inductive categories

\begin{tabular}{|c|c|c|c|}
\hline \multirow[b]{2}{*}{ Category } & \multicolumn{2}{|c|}{$\begin{array}{l}\text { Coding } \\
\text { units }\end{array}$} & \multirow[b]{2}{*}{ Text example } \\
\hline & $n$ & $\%$ & \\
\hline \multicolumn{4}{|l|}{ Personal-level antecedents } \\
\hline Achievement motivation & 13 & 4.39 & $\begin{array}{l}\text { Professional ethics (...) are extremely high developed among pilots } \\
\text { (pos. 62) }\end{array}$ \\
\hline Trust, in the reporting system & 11 & 3.72 & This is also a question of trust in the reporting system (pos. 182) \\
\hline Need to communicate & 8 & 2.70 & $\begin{array}{l}\text { I think it is simply a type question, someone who is talkative, tends to } \\
\text { write two or more pages (pos. 117) }\end{array}$ \\
\hline \multicolumn{4}{|l|}{ Contextual-level antecedents } \\
\hline Behavior of safety department & 12 & 4.05 & $\begin{array}{l}\text { An information booth can also be useful to give pilots an understanding } \\
\text { of our work (pos. 260) }\end{array}$ \\
\hline Reporting system, personal option & 8 & 2.70 & $\begin{array}{l}\text { It is not rare that pilots come and say: "Let me tell you something" } \\
\text { (pos. 29) }\end{array}$ \\
\hline Reporting system, transparent report processing & 8 & 2.70 & $\begin{array}{l}\text { I do not know the processing procedure and the person behind it - } \\
\text { therefore it is a clear barrier to admit one's own mistakes (pos. 63) }\end{array}$ \\
\hline Behavior of managers & 4 & 1.35 & $\begin{array}{l}\text { The fleet chief was writing something and realized what I was asking } \\
\text { and raised his hand to admit having committed an error (pos. 69) }\end{array}$ \\
\hline Country-related culture & 3 & 1.01 & $\begin{array}{l}\text { Pilots know that reports are not handled in the same way in all } \\
\text { countries of the world. The honest report you write will be used against } \\
\text { you (pos. 126). }\end{array}$ \\
\hline \multicolumn{4}{|l|}{ Goal-related factors } \\
\hline Goal, reduce individual liability concerns & 13 & 4.39 & $\begin{array}{l}\text { They report so that it is documented, even if there was no risk at } \\
\text { all (pos. 93) }\end{array}$ \\
\hline Extrinsic incentives & 10 & 3.38 & $\begin{array}{l}\text { If pilots take the time to report, it should be paid duty } \\
\text { time (pos. 329) }\end{array}$ \\
\hline Notification of incident & 8 & 2.70 & $\begin{array}{l}\text { I did not know that this was such a severe case or that it looked so } \\
\text { serious (pos. 201) }\end{array}$ \\
\hline Workload, writing a report & 8 & 2.70 & It is simple: It is an effort to report something (pos. 12) \\
\hline Goal, initiate safety-related change & 7 & 2.36 & I have recognized a deficiency and would like to eliminate it (pos. 274) \\
\hline Understanding the purpose of a procedure & 7 & 2.36 & $\begin{array}{l}\text { The less a pilot understands a procedure, the less they file a report } \\
\text { (pos. 154) }\end{array}$ \\
\hline Goal, enable learning from incidents & 6 & 2.03 & Sharing their experiences with other pilots (pos. 198) \\
\hline Goal, ease one's conscience & 4 & 1.35 & I write a report to ease my conscience (pos. 98) \\
\hline Procrastination & 4 & 1.35 & $\begin{array}{l}\text { What happens: I wanted to file a report, but went on vacation and } \\
\text { forgot about it (pos. 192) }\end{array}$ \\
\hline Severity of incident, change in individual evaluation & 3 & 1.01 & An event loses its momentum after two nights have passed (pos. 296) \\
\hline Responsibility for incident & 2 & 0.68 & $\begin{array}{l}\text { The worst thing is to report something that I really messed up } \\
\text { (pos. 111) }\end{array}$ \\
\hline Reputation concerns & 2 & 0.68 & $\begin{array}{l}\text { Whoever is prominent within the organization or is personally known to } \\
\text { the safety department feels inhibited to speak freely (pos. 235) }\end{array}$ \\
\hline
\end{tabular}

Note. Categories that were also addressed as part of the experts' mind map are indicated in bold.

To answer the research question of which endogenous and exogenous motivational factors influence the voluntary reporting behavior of commercial pilots' self-inflicted incidents, the factors shown in Tables 3 and 4 are summarized in Figure 3.

\section{Contingency Analysis}

Joint encoding of coding units was evaluated in contingency analyses. The following section describes in more detail which influencing factors showed the most joint encodings; categories with the most frequent joint encodings are described first.

\section{Severity of Incident, Individual Evaluation}

The category "Severity of incident, individual evaluation" was used 19 times jointly with other categories. The individual evaluation often differs from that in the safety department, due to the fact that the organizational relevance of a single event often cannot be correctly assessed by pilots, as "frequencies in relation to total flight movements" (pos. 94; 96) are not known to the pilots. A pilot's commitment of doing the job well is also reflected in the individual assessment of an incident: In an example from the cockpit with an incorrectly set but after a few minutes corrected air pressure (QNH), there are pilots for whom "nothing happened," whereas others say, "Two minutes flying with 


\begin{tabular}{|c|c|c|}
\hline Exogenous Motivational Processes & Endogenous Motivational Processes & Exogenous Motivational Processes \\
\hline $\begin{array}{l}\quad \text { Personal-level antecedents } \\
\text { Achievement motivation } \\
\text { Fear, disciplinary action } \\
\text { Need to communicate } \\
\text { Risk- taking attitudes } \\
\text { Shame } \\
\text { Trust, general } \\
\text { Trust, in the reporting system } \\
\end{array}$ & $\begin{array}{l}\text { Goal-choice } \\
\text { Causes of incident } \\
\text { Clarity on what constitutes a reportable incident } \\
\text { Feedback, prior experience } \\
\text { Goal, ease one's conscience } \\
\text { Goal, enable learning from incidents } \\
\text { Goal, initiate safety-related change } \\
\text { Goal, reduce individual liability concerns }\end{array}$ & \\
\hline $\begin{array}{l}\quad \text { Contextual-level antecedents } \\
\text { Behavior of safety department } \\
\text { Behavior of colleagues } \\
\text { Behavior of management } \\
\text { Country-related culture } \\
\text { Non-punitive environment } \\
\text { Reporting system, confidential option } \\
\text { Reporting system, feedback on a report } \\
\text { Reporting system, personal option } \\
\text { Reporting system, transparent report processing } \\
\text { Reporting system, user-friendly } \\
\text { Safety cultural aspects } \\
\end{array}$ & $\begin{array}{l}\text { Reputation concerns } \\
\text { Responsibility for incident } \\
\text { Severity of incident, individual evaluation } \\
\text { Severity of incident, change in individual evaluation } \\
\text { Understanding a procedure's purpose }\end{array}$ & $\begin{array}{l}\text { Optimal functioning at work } \\
\text { Pilots' voluntary reporting behavior }\end{array}$ \\
\hline
\end{tabular}

Figure 3. Factors influencing pilots' voluntary reporting behavior. Simplified representation of the heuristic conceptual motivational framework according to van den Broeck et al. (2019); deductive and inductive categories from Tables 3 and 4 are included as exogenous and endogenous motivational factors and presented in alphabetical order.

the wrong QNH, I absolutely have to report this" (pos. 91). This individual assessment can "even be different in the same cockpit" (pos. 216) and is also viewed critically by experts because pilots sometimes, "do not perceive incidents as severe as they are in reality" (pos. 215). Less serious incidents are often reported in the form of a "two-line report" (pos. 195) constituting an "alibi report" (pos. 98) with the goal of reducing individual liability concerns to be protected within the framework of a just culture environment if the incident becomes known through other data sources such as flight data analyses. It happens that incident reports are not written because crews did not even notice the incident. A conversation about an incident is reported in which the bank angle of the aircraft was no more than 25 degrees in the pilot's perception, while it was 50 degrees in the flight data recording (pos. 204). The individual assessment of the severity of an incident can change in the time after an incident. "Two nights later" (pos. 296) or after being back to "private life with its events, family, and appointments" (pos. 297), incidents will sometimes be considered less serious. A lack of clear definitions of which incidents require a report increases the pilots' uncertainty about whether "it is worth writing a report" (pos. 94). Especially reports about incidents with increased severity are written with the goal of "sharing experiences with other pilots" (pos. 198). In the perception of the experts, these reports are often written in greater detail (pos. 119).

\section{Behavior of Safety Department}

The category "Behavior of safety department" was used 19 times jointly with other categories. For a positive public appearance of the safety department, "constant advertising of the value system" (pos. 331), regular "personal contact" (pos. 127) and, with regard to confidential reporting, constant emphasis that above all what is "reported between the lines" (pos. 127) is handled confidentially are necessary. The behavior of the safety department is therefore closely related to the pilots' trust in the reporting system. A positive public appearance is also connected to the fact that pilots also write reports with the goal of "easing their conscience" (pos. 98) when they have experienced something "dramatic for them" (pos. 280).

\section{Reporting System, Confidential Option}

The category "Reporting system, confidential option" was used 18 times jointly with other categories. Pilots tend to use confidential reporting options to be able to "shoot from cover" (pos. 181) because of fear of disciplinary action. Pilots who lack confidence in the reporting system tend to "build a small protective cover for themselves with a confidential report" (pos. 159). However, this behavior clashes with the fact that particularly some of the incidents described in confidential reports are those for which superiors should actually "take disciplinary action" (pos. 187). Persons who feel a greater need to communicate tend to report 
confidentially "to illuminate the background" (pos. 161). In case of a "lack of trust in just culture principles," confidential reports are still frequently written "as a precaution" (pos. 160). Transparent report processing seems to be particularly relevant for confidential reports, because pilots want to know "what happens to the report" and "want to trust the people who evaluate reports" (pos. 263).

\section{Shame}

The category "Shame" was used 17 times jointly with other categories. Shame "to come clean" is especially pronounced when pilots have to admit that they "didn't have it in them" (pos. 63) and is related to the incident causes. "A rule violation is less likely to be reported than an unintentional error" (pos. 145) because reporting a violation implies the shame of admitting to having "reached their limits with a trait" (pos. 64). The experts again underline that "it is certainly much easier to report errors that are outside one's own area of responsibility (pos. 159)". Pilots are least eager to admit that they have "reached their limits" (pos. 64) or that the incident was caused by a limited "proficiency in terms of lack of manual flight skills" (pos. 146) considered to be the "most basic skill" (pos. 146) that pilots "want to be good at" (pos. 62; e.g., "I want to be very conscientious and now such a big failure happened to me," pos. 59). This aspect is closely related to the fact that pilots often show "a strong achievement motivation" (pos. 62). This motivation increases the more responsibility a pilot is given, for example, becoming an instructor ("now that you are chief instructor, no more errors should happen to you," pos. 71). In this context, the experts describe that it takes a long time "until the severe cases come to light" (pos. 89) in informal discussions. Shame is often accompanied by reputation concerns: It is assumed that shame is particularly pronounced among pilots who are "prominent within the organization or are personally known to the safety department" (pos. 235).

\section{Reporting System, Feedback on a Report}

The category "Reporting system, feedback on a report" was used 16 times jointly with other categories. Feedback is vital, especially when the goal of a report is to ease one's conscience: Pilots are "extremely thankful" that someone contacts them and the incident "does not simply vanish unseen" (pos. 283). It is also important when the pilot's goal is "to initiate change" (pos. 141) or they want to "enable others [in] learning from [one's] own incidents" (pos. 274) as this indicates "that someone is working on the problem and is trying to change it" (pos. 274). This is usually the case when it is "not an isolated incident" (pos. 61) and the responsibility for the incident also lies with the airline. An established feedback process also seems to be conducive to the perceived behavior of the safety department by the pilots, because incident reports are often "written in a spirit of trust, and if there is no feedback, no second report will be written" (pos. 270). Feedback also promotes the pilots' confidence in the reporting system, so that they are "much more willing to report if there is anything unpleasant to report" (pos. 285). The experts recommend sending a standard feedback letter, if a large number of incoming reports means that it is not possible to respond to each one individually (pos. 278).

The numerous relations described underline that pilots' voluntary reporting behavior on self-inflicted incidents can only be understood from a holistic perspective of exogenous and endogenous motivational processes.

\section{Discussion}

The aim of this study was to identify factors that influence the pilots' voluntary reporting behavior on self-inflicted incidents and to consider them from a motivational perspective. After interviewing commercial aviation experts with experience in accident investigation and reporting, we derived 36 factors that influence exogenous or endogenous motivational processes of pilots when voluntarily reporting incidents.

We were able to show that factors being identified to impact overall reporting of HRO members, for example, shame or the individual assessment of the severity of an incident, also influence the voluntary reporting behavior of pilots' self-inflicted incidents. We could expand the field of HRO research concerning reporting especially in the area of endogenous motivational processes in individual goal-choice and goal-striving when reporting: Pilots do write incident reports with concrete goals, for example, to initiate safety-related change or to reduce individual liability concerns. Goal-striving can be influenced by intrinsic factors, such as the achievement motivation of a pilot, and extrinsic factors, such as payment for the duty time necessary to write a report.

The motivational framework model of van den Broeck et al. (2019) was a helpful model to consider the motivational factors influencing pilots' reporting behavior: Due to the high number of categories, in the following section we only discuss a selection of factors that were most frequently used to code text segments in the transcript.

In the area of personal-level antecedents, the momentary state of shame was identified to impair pilots' voluntary reporting behavior. Our results suggest that shame affects reporting behavior in the context of commercial aviation as much as in the chemical industry (van der Schaaf \& Kanse, 2004) or in clinical settings (Zabari \& Southern, 2018). Within the contingency analysis it became evident 
that shame can also be related to personal reputation concerns. It might seem plausible that pilots do not want to constrain their motive for status (Anderson et al., 2015) and do not want to harm their own reputation (Blickle \& Hogan, 2017) by reporting a self-inflicted incident.

Interrelations between personal and contextual antecedents can be illustrated by the fact that confidential reporting systems are used primarily when pilots lack trust in a just culture. Our findings thus extend the well-known reasons given by Langer (2016) for why organization members make use of confidential reporting and confirm the results of McMurtrie and Molesworth (2018) that pilots refrain from reporting due to limited trust in just culture.

In the area of contextual-level antecedents, feedback is one of the factors most frequently mentioned by the experts. Our results highlight the relevance of feedback in terms of "optimal functioning at work" of an organization member and as a core activity dimension in the job characteristics model (Hackman \& Oldham, 1976; Margaryan et al., 2017; van den Broeck et al., 2019). In this regard, according to the experience of the experts, a pilot's individual perception that a colleague receives positive feedback for their report might reinforce their own reporting behavior through vicarious reinforcement and imitation processes (cf. Bandura, 1986; Spada et al., 2006). We also underline the findings of Curcuruto et al. (2015) that appropriate communication strategies can promote the safety behavior of organization members from the perspective of human resource management. The interrelation of feedback with the individual goal to initiate safety-related change confirms the research of Nykänen et al. (2019) that feedback improves the individual locus of control. Regardless of the importance of feedback in reporting, only about one fifth of the experts' statements contained contextual antecedents related to the reporting system; this underscores the conclusion of van der Westhuizen and Stanz (2017) that reporting behavior cannot be understood solely by scrutinizing the reporting system.

Endogenous motivational, goal-related factors were shown to influence voluntary reporting behavior: Pilots write reports with the goal of documenting an incident in order to reduce personal liability concerns; this confirms the results of a research paper by Maslen et al. (2020) on the reporting behavior of engineers. The goal of initiate safety-related change with a report is consistent with one dimension of the SCB proposed by Hofmann et al. (2003) and Wishart et al. (2019). Monetary incentives can positively impact pilots' goal-striving when voluntarily reporting incidents. Principally monetary incentives might be regarded to be an extrinsic contingency factor with reference to the two-factor theory (Herzberg et al., 1959). However, the state of research concerning the effects of payment on motivation remains ambiguous (Gerhart \& Fang, 2015). Moreover, monetary incentives were only addressed by the experts when asked whether important aspects had been neglected. This underscores the comments of van den Broeck et al. (2019) that "remarkably few studies have explicitly examined the impact of monetary rewards on employee performance" such as the voluntary reporting of incidents (p. 356).

We were able to show that incident-related aspects such as the causes of an incident or the pilot's severity evaluation of the incident can have an influence on the voluntary reporting behavior of the incident, thus confirming the findings of Sieberichs and Kluge (2018). When evaluating the severity of an incident, there are often discrepancies between the pilots' and the airline's assessment. This supports the findings of Scheer et al. (2010) that the perception of damage potential often differs between different stakeholders. The change in individual assessment after a few days can be attributed to the fallibility of human memory (cf. Abrahamsson et al., 2010). The finding that pilots sometimes do not recognize an occurrence to be an incident and therefore do not report it confirms the research by Drupsteen and Hasle (2014) that the lack of recognition of a hazardous situation can be a bottleneck for LFI. Comparable findings are also available in other sectors, such as shipping (Hasanspahić et al., 2020). The results also coincide with the findings of a study by Thomas (2004), in which pilots identified only about half of the potential risk sources.

\section{Limitations}

When planning the expert focus group, attention was paid to establishing a relationship of trust between the interview participants; therefore, executives were not invited, for example. However, effects due to a social desirability of the answers cannot be ruled out in the course of the reflected subjectivity of the researchers, as moderators and experts were personally acquainted with each other (Steinke, 2019).

However, we consider socially desirable response behavior less problematic, as socially desirable opinions are difficult to represent credibly to a group (Schulz et al., 2012).

Even though the experts were asked whether important aspects were not addressed so as to give them leeway to make statements regarding the research topic, the "unfolding of subjective meaning" (Helfferich, 2019, p. 684) was limited by confining the dimension of openness and structuring the interview more strongly through questions. As a consequence, aspects relevant to the research question may not have been sufficiently captured (Steinke, 2019).

At the end of the interview, the mind map was created in only a few minutes and, with 12 factors, contained only a few of the aspects addressed in the interview. This result in combination with the moderators' perception of the 
participants' exhaustion suggests that breaks were not sufficiently considered in the schedule.

A comparison of different points of view within the expert group was not possible by applying a so-called absolute anonymization (cf. Medjedović \& Witzel, 2010) of the interview data. Furthermore, no analyses of group effects or gestures and facial expressions of the participants were conducted (cf. Schulz et al., 2012).

To ensure intersubjective comprehensibility, we paid attention to an exact documentation of the research process and the use of codified procedures (cf. Steinke, 2019); however, the transcript was only coded by individuals and not in a group, as suggested by Rust (2018), for example.

Although the definition of a complete statement of a participant as a coding and context unit is justifiable on the basis of the chosen procedure (cf. Ruin, 2019), the category system does not meet the criterion to be disconnected. The value for the evaluator agreement is in a very good range; nevertheless, the informative value of kappa coefficients is limited in the context of qualitative content analyses (cf. Rädiker \& Kuckartz, 2019).

An empirical anchoring (cf. Steinke, 2019) could only be presented after the original German statement of the experts had been translated into English. The generalizability of the results may be limited by the fact that all experts are employed by the same European-based airline. Various facets of fear (e.g., lost group's scorecard points or unfair performance evaluation) were not addressed. However, we justify the decision to end data collection because we reached a saturating level of new information with the selected experts to answer the research question for pilots in Western cultures.

Regardless of the limitations described above, this research fulfills the criteria of a "significant contribution" to a "worthy topic" (Strübing et al., 2018; Tracy \& Hinrichs, 2017): We were able to expand the body of research on factors influencing the voluntary reporting behavior of commercial pilots and thus contribute to supporting the ability of airlines to learn from incidents identified as one of the safety-related drivers by IATA (2019) in the Introduction.

\section{Implications for Research}

The strength of the effects of the derived influencing factors on the report behavior should be checked by inferential statistical analysis. The extent of the difference in the assessment of the severity of an incident between the pilot and the airline might be further investigated to derive concrete recommendations as to which incidents require a report (cf. Stemn et al., 2018). The different facets of fear when writing a report might be examined in the context of further research to obtain indications of cultural facets that hinder reporting. The motivation to report a self- inflicted incident is a necessary, but not yet sufficient, condition for a report to be written. Future research might consider reporting behavior from the perspective of the theory of planned behavior (Ajzen, 1991) and investigate how factors such as issues with report writing or procrastination affect behavioral intention and behavior.

\section{Implications for Airlines}

Airlines might consider the contextual factors derived in this study. Primarily, this includes confidential reporting options so that pilots can report self-inflicted incidents even though they may lack confidence in a just culture. The more user-friendly airlines design their reporting systems, the greater the likelihood that pilots will be able to write their report without failing due to the aforementioned barriers. Our results again underline the relevance of feedback on incident reports, especially when the author's goal is to initiate a change or to "get rid" of an incriminating event. In addition, feedback as well as transparent report processing is related to a positive public appearance of the safety department. Airlines could also consider the possibility of supporting the reporting behavior of their pilots with extrinsic incentives, such as paying for the time required for reporting. They should also clarify which incidents require reporting and encourage pilots to report regardless of their individual assessment on the severity of the incident.

If airlines consider the contextual antecedents that are conducive to voluntary reporting behavior and support their pilots in the course of the endogenous motivational processes mentioned in this study, the drivers identified by IATA (2019) can be supported and it will be easier for pilots to "come clean" - even when reporting self-inflicted incidents voluntarily.

\section{References}

Abrahamsson, M., Hassel, H., \& Tehler, H. (2010). Towards a systemoriented framework for analysing and evaluating emergency response. Journal of Contingencies and Crisis Management, 18(1), 14-25. https://doi.org/10.1111/j.1468-5973.2009. 00601.x

Ajzen, I. (1991). The theory of planned behavior. Organizational Behavior and Human Decision Processes, 50(2), 179-211. https://doi.org/10.1016/0749-5978(91)90020-T

Altman, D. G. (1990). Practical statistics for medical research. CRC Press.

Anderson, C., Hildreth, J. A. D., \& Howland, L. (2015). Is the desire for status a fundamental human motive? A review of the empirical literature. Psychological Bulletin, 141(3), 574-601. https://doi.org/10.1037/a0038781

Bandura, A. (1986). Social foundations of thought and action: A social cognitive theory. Prentice-Hall.

Barach, P. (2000). Reporting and preventing medical mishaps: Lessons from non-medical near miss reporting systems. British Medical Journal, 320(7237), 759-763. https://doi.org/10.1136/ bmj.320.7237.759 
Blickle, G., \& Hogan, R. (2017). Socioanalytic perspective. In V. Zeigler-Hill \& T. K. Shackelford (Eds.), Encyclopedia of personality and individual differences (pp. 1-5). Springer International Publishing. https://doi.org/10.1007/978-3-31928099-8_1186-1

Brennan, R. L., \& Prediger, D. J. (1981). Coefficient kappa: Some uses, misuses, and alternatives. Educational and Psychological Measurement, 41(3), 687-699. https://doi.org/10.1177/ 001316448104100307

Bühler, K. (1999). Sprachtheorie: Die Darstellungsfunktion der Sprache (Ungekürzter Neudr. d. Ausg. Jena, Fischer, 1934) [The representational function of language]. Uni-Taschenbücher: Vol. 1159. Fischer

Chen, C.-F., \& Chen, S.-C. (2014). Measuring the effects of safety management system practices, morality leadership and selfefficacy on pilots' safety behaviors: Safety motivation as a mediator. Safety Science, 62, 376-385. https://doi.org/ 10.1016/j.ssci.2013.09.013

Cohn, R. C. (2000). Von der Psychoanalyse zur themenzentrierten Interaktion. Von der Behandlung einzelner zu einer Pädagogik für alle [From psychoanalysis to theme-centered interaction. From the treatment of individuals to a pedagogy for all]. Klett-Cotta.

Conchie, S. M. (2013). Transformational leadership, intrinsic motivation, and trust: A moderated-mediated model of workplace safety. Journal of Occupational Health Psychology, 18(2), 198-210. https://doi.org/10.1037/a0031805

Curcuruto, M., Conchie, S. M., Mariani, M. G., \& Violante, F. S. (2015). The role of prosocial and proactive safety behaviors in predicting safety performance. Safety Science, 80, 317-323. https://doi.org/10.1016/j.ssci.2015.07.032

Curcuruto, M., \& Griffin, M. A. (2018). Prosocial and proactive "safety citizenship behaviour" (SCB): The mediating role of affective commitment and psychological ownership. Safety Science, 104(104), 29-38. https://doi.org/10.1016/j.ssci.2017.12.010

Dekker, S. (2018). Just culture: Restoring trust and accountability in your organization. CRC Press.

Didla, S., Mearns, K., \& Flin, R. (2009). Safety citizenship behaviour: A proactive approach to risk management. Journal of Risk Research, 12(3), 475-483. https://doi.org/10.1080/ 13669870903041433

Drupsteen, L., Groeneweg, J., \& Zwetsloot, G. I. (2013). Critical steps in learning from incidents: Using learning potential in the process from reporting an incident to accident prevention. International Journal of Occupational Safety and Ergonomics, 19(1), 63-77. https://doi.org/10.1080/10803548.2013.11076966

Drupsteen, L., \& Guldenmund, F. W. (2014). What is learning? A review of the safety literature to define learning from incidents, accidents and disasters. Journal of Contingencies and Crisis Management, 22(2), 81-96. https://doi.org/10.1111/14685973.12039

Drupsteen, L., \& Hasle, P. (2014). Why do organizations not learn from incidents? Bottlenecks, causes and conditions for a failure to effectively learn. Accident Analysis \& Prevention, 72 , 351-358. https://doi.org/10.1016/j.aap.2014.07.027

Drupsteen, L., \& Wybo, J.-L. (2015). Assessing propensity to learn from safety-related events. Safety Science, 71, 28-38. https:// doi.org/10.1016/j.ssci.2014.02.024

European Parliament. (2014). Regulation (EU) no. 376/2014 of the European Parliament and of the Council of 3 April 2014 on the reporting, analysis and follow-up of occurrences in civil aviation, amending regulation (EU) no. 996/2010 of the European Parliament and of the Council and repealing directive 2003/42/EC of the European Parliament and of the Council and Commission regulations (EC) no. 1321/2007 and (EC) no. 1330/ 2007. Official Journal of the European Union, (L122), 18-43.
https://eur-lex.europa.eu/legal-content/EN/TXT/?qid=157624 553 2595\&uri=CELEX\%3A32014R0376

Gerhart, B., \& Fang, M. (2015). Pay, intrinsic motivation, extrinsic motivation, performance, and creativity in the workplace: Revisiting long-held beliefs. Annual Review of Organizational Psychology and Organizational Behavior, 2(1), 489-521. https:// doi.org/10.1146/annurev-orgpsych-032414-111418

Gilbey, A., Tani, K., \& Tsui, W. H. K. (2016). Outcome knowledge and under-reporting of safety concerns in aviation. Applied Cognitive Psychology, 30(2), 141-151. https://doi.org/10.1002/acp.3179

Griffin, M. A., \& Curcuruto, M. (2016). Safety climate in organizations. Annual Review of Organizational Psychology and Organizational Behavior, 3(1), 191-212. https://doi.org/10.1146/ annurev-orgpsych-041015-062414

Griffin, M. A., \& Neal, A. (2000). Perceptions of safety at work: A framework for linking safety climate to safety performance, knowledge, and motivation. Journal of Occupational Health Psychology, 5(3), 347-358. https://doi.org/10.1037/1076-8998. 5.3.347

Hackman, J., \& Oldham, G. R. (1976). Motivation through the design of work: Test of a theory. Organizational Behavior and Human Performance, 16(2), 250-279. https://doi.org/10.1016/ 0030-5073(76)90016-7

Hasanspahić, N., Frančić, V., Vujičić, S., \& Maglić, L. (2020). Reporting as a key element of an effective near-miss management system in shipping. Safety, 6(4), Article 53. https://doi. org/10.3390/safety6040053

Haslbeck, A., Schubert, E., \& Schmidt-Moll, C. (2015). Pilots' willingness to report aviation incidents. In 18th International Symposium on Aviation Psychology (ISAP 2015), Dayton, Ohio, USA, 4-7 May 2015 (pp. 596-600). Curran.

Hedlund, A., Åteg, M., Andersson, I.-M., \& Rosén, G. (2010). Assessing motivation for work environment improvements: Internal consistency, reliability and factorial structure. Journal of Safety Research, 41(2), 145-151. https://doi.org/10.1016/j.jsr.2009.12.005

Helfferich, C. (2019). Leitfaden- und Experteninterviews [Guided and expert interviews]. In N. Baur \& J. Blasius (Eds.), Handbuch Methoden der empirischen Sozialforschung (pp. 669-686). Springer Fachmedien. https://doi.org/10.1007/978-3-65821308-4_44

Herzberg, F., Snyderman, B. B., \& Mausner, B. (1959). The motivation to work (2nd ed.). Wiley.

Hofmann, D. A., Morgeson, F. P., \& Gerras, S. J. (2003). Climate as a moderator of the relationship between leader-member exchange and content specific citizenship: Safety climate as an exemplar. Journal of Applied Psychology, 88(1), 170-178. https://doi.org/10.1037/0021-9010.88.1.170

International Air Transport Association. (2019). I-ASC whitepaper: Creating a positive safety culture. https://www.iata.org/en/ services/safety-flight-operations/i-asc/

International Air Transport Association. (2020). Safety report 2019 (56th ed.). https://www.iata.org/en/publications/safety-report/ International Civil Aviation Organization. (2013). Eccairs aviation data definition standard. https://www.icao.int/safety/airnavigation/ AIG/Documents/ADREP\%20Taxonomy/ECCAIRS\%20Aviation\% 201.3.0.12\%20(VL\%20for\%20AttrID\%20\%20431\%20-\% 200ccurrence\%20Classes).pdf

International Civil Aviation Organization. (2019). Requirements of annex 13 ana sms. https://www.icao.int/NACC/Documents/ Meetings/2019/SMSANSP/SMSxANSP-P07.pdf

Jausan, M., Silva, J., \& Sabatini, R. (2017). A holistic approach to evaluating the effect of safety barriers on the performance of safety reporting systems in aviation organisations. Journal of Air Transport Management, 63, 95-107. https://doi.org/ 10.1016/j.jairtraman.2017.06.004 
Krueger, R. A., \& Casey, M. A. (2014). Focus groups: A practical guide for applied research. SAGE Publications.

Landis, J. R., \& Koch, G. G. (1977). The measurement of observer agreement for categorical data. Biometrics, 33(1), 159-160. https://doi.org/10.2307/2529310

Langer, C. (2016). Improving safety culture with confidential reporting. Proceedings of the Human Factors and Ergonomics Society Annual Meeting, 60(1), 1612-1616. https://doi.org/ 10.1177/1541931213601372

Littlejohn, A., Lukic, D., \& Margaryan, A. (2014). Comparing safety culture and learning culture. Risk Management, 16(4), 272-293. https://doi.org/10.1057/rm.2015.2

Margaryan, A., Littlejohn, A., \& Stanton, N. A. (2017). Research and development agenda for learning from incidents. Safety Science, 99, 5-13. https://doi.org/10.1016/j.ssci.2016.09.004

Maslen, S., Hayes, J., Wong, J., \& Scott-Young, C. (2020). Witch hunts and scapegoats: An investigation into the impact of personal liability concerns on engineers' reporting of risks. Environment Systems and Decisions, 40(3), 413-426. https:// doi.org/10.1007/s10669-020-09757-0

Mayring, P. (2015). Qualitative Inhaltsanalyse: Grundlagen und Techniken (12. überarbeitete Auflage) [Qualitative content analysis: Basics and techniques (12th., rev. ed.)]. Beltz.

Mayring, P. (2016). Einführung in die qualitative Sozialforschung [Introduction to qualitative social research]. Beltz.

Mayring, P. (2020). Qualitative Forschungsdesigns [Qualitative research designs]. In G. Mey \& K. Mruck (Eds.), Handbuch qualitative Forschung in der Psychologie: Band 2: Designs und Verfahren (2nd ed., pp. 1-17). Springer Fachmedien.

Mayring, P., \& Fenzl, T. (2019). Qualitative Inhaltsanalyse [Qualitative content analysis]. In N. Baur \& J. Blasius (Eds.), Handbuch Methoden der empirischen Sozialforschung (pp. 633-648). Springer Fachmedien. https://doi.org/10.1007/9783-658-21308-4_42

McMurtrie, K. J., \& Molesworth, B. R. C. (2018). Australian flight crews' trust in voluntary reporting systems and just culture policies. Aviation Psychology and Applied Human Factors, 8(1), 11-21. https://doi.org/10.1027/2192-0923/a000131

Medjedović, I., \& Witzel, A. (2010). Wiederverwendung qualitativer Daten: Archivierung und Sekundärnutzung qualitativer Interviewtranskripte (1. Aufl.) [Reuse of qualitative data: Archiving and secondary use of qualitative interview transcripts (1 st ed.)]. VS, Verl. für Sozialwiss.

Merry, A. F., \& Henderson, B. (2017). Incident reporting, aviation and anaesthesia. Anaesthesia and Intensive Care, 45(3), 291-294. https://doi.org/10.1177/0310057X1704500304

Mitchell, I., Schuster, A., Smith, K., Pronovost, P., \& Wu, A. (2016). Patient safety incident reporting: A qualitative study of thoughts and perceptions of experts 15 years after 'to err is human'. BMJ Quality \& Safety, 25(2), 92-99. https://doi.org/ 10.1136/bmjqs-2015-004732

Nykänen, M., Salmela-Aro, K., Tolvanen, A., \& Vuori, J. (2019). Safety self-efficacy and internal locus of control as mediators of safety motivation - randomized controlled trial (RCT) study. Safety Science, 117, 330-338. https://doi.org/10.1016/j.ssci. 2019.04.037

Parker, S. K., Bindl, U. K., \& Strauss, K. (2010). Making things happen: A model of proactive motivation. Journal of Management, 36(4), 827-856. https://doi.org/10.1177/0149206310363732

Petitta, L., Probst, T. M., \& Barbaranelli, C. (2017). Safety culture, moral disengagement, and accident underreporting. Journal of Business Ethics, 141(3), 489-504. https://doi.org/10.1007/ s10551-015-2694-1

Probst, T. M., \& Estrada, A. X. (2010). Accident under-reporting among employees: Testing the moderating influence of psychological safety climate and supervisor enforcement of safety practices. Accident Analysis \& Prevention, 42(5), 1438-1444. https://doi.org/10.1016/j.aap.2009.06.027

Rädiker, S., \& Kuckartz, U. (2019). Analyse qualitativer Daten mit MAXQDA: Text, Audio und Video [Analysis of qualitative data with MAXQDA: Text, audio and video]. Springer Fachmedien.

Reason, J. T. (1998). Achieving a safe culture: Theory and practice. Work \& Stress, 12(3), 293-306. https://doi.org/10.1080/ 02678379808256868

Reason, J. T. (2016). Managing the risks of organizational accidents. Routledge.

Renner, K. H., \& Jacob, N. C. (2020). Das Interview [The Interview]. Springer.

Ruin, S. (2019). Kategorien als Ausdruck einer ausgewiesenen Beobachter/innenperspektive? Ein Vorschlag für eine qualitativere qualitative Inhaltsanalyse [Categories as an expression of a designated observer perspective? A proposal for a more qualitative content analysis]. Forum Qualitative Sozialforschung. Advance online publication. https://doi.org/ 10.17169/FQS-20.3.3395

Rust, I. (2018). Theoriegenerierung im Rahmen der qualitativen Inhaltsanalyse [Theory generation in the context of qualitative content analysis]. https://doi.org/10.13140/RG.2.2.19060.60806

Sawhney, G., \& Cigularov, K. P. (2019). Examining attitudes, norms, and control toward safety behaviors as mediators in the leadership-safety motivation relationship. Journal of Business and Psychology, 34(2), 237-256. https://doi.org/10.1007/ s10869-018-9538-9

Scheer, D., Gold, S., Benighus, C. B. L. O. J., \& Renn, O. (2010) Kommunikation von Risiko und Gefährdungspotenzial aus Sicht verschiedener stakeholder [Communication of risk and hazard potential from the perspective of various stakeholders]. BfRWissenschaft, 1, 111-116.

Schreier, M. (2012). Qualitative content analysis in practice. SAGE Publications.

Schulz, M., Mack, B., \& Renn, O. (2012). Fokusgruppen in der empirischen Sozialwissenschaft [Focus groups in empirical social science]. Beltz Verlag.

Sieberichs, S., \& Kluge, A. (2018). Influencing factors on error reporting in aviation - a scenario-based approach. In N. A. Stanton (Ed.), Advances in intelligent systems and computing: Advances in human aspects of transportation (Vol. 597, pp. 3-14). Springer International Publishing. https://doi.org/ 10.1007/978-3-319-60441-1_1

Spada, H., Rummel, N., \& Ernst, A. (2006). Lernen [Learning]. In H. Spada (Ed.), Lehrbuch allgemeine Psychologie [Teaching book general psychology] (pp. 343-434). Huber.

Steinke, I. (2019). Gütekriterien qualitativer Forschung [Quality criteria of qualitative research]. In U. Flick (Ed.), Qualitative Sozialforschung (pp. 319-331). Beltz Verlag.

Stemn, E., Bofinger, C., Cliff, D., \& Hassall, M. E. (2018). Failure to learn from safety incidents: Status, challenges and opportunities. Safety Science, 101, 313-325. https://doi.org/10.1016/j. ssci.2017.09.018

Strübing, J., Hirschauer, S., Ayaß, R., Krähnke, U., \& Scheffer, T. (2018). Gütekriterien qualitativer sozialforschung. Ein Diskussionsanstoß [Quality criteria of qualitative social research. An impetus for discussion]. Zeitschrift für Soziologie, 47(2), 83-100. https://doi.org/10.1515/zfsoz-2018-1006

Thomas, M. J. W. (2004). Predictors of threat and error management: Identification of core nontechnical skills and implications for training systems design. The International Journal of Aviation Psychology, 14(2), 207-231. https://doi.org/10.1207/ s15327108ijap1402_6

Tracy, S. J. (2010). Qualitative quality: Eight "big-tent" criteria for excellent qualitative research. Qualitative Inquiry, 16(10), 837-851. https://doi.org/10.1177/1077800410383121 
Tracy, S. J., \& Hinrichs, M. M. (2017). Big tent criteria for qualitative quality. In J. Matthes, C. S. Davis, \& R. F. Potter (Eds.), The international encyclopedia of communication research methods (pp. 1-10). Wiley. https://doi.org/10.1002/ 9781118901731.iecrm0016

Van den Broeck, A., Carpini, J. A., \& Diefendorff, J. M. (2019). Work motivation. In R. M. Ryan, A. van den Broeck, J. A. Carpini, \& J. M. Diefendorff (Eds.), The Oxford handbook of human motivation (pp. 506-524). Oxford University Press. https://doi. org/10.1093/oxfordhb/9780190666453.013.27

Van der Schaaf, T., \& Kanse, L. (2004). Biases in incident reporting databases: An empirical study in the chemical process industry. Safety Science, 42(1), 57-67. https://doi.org/10.1016/ S0925-7535(03)00023-7

Van der Westhuizen, J., \& Stanz, K. (2017). Critical incident reporting systems: A necessary multilevel understanding. Safety Science, 96, 198-208. https://doi.org/10.1016/j.ssci.2017.04. 004

Weick, K. E., \& Sutcliffe, K. M. (2007). Managing the unexpected. Jossey-Bass.

Wishart, D., Rowland, B., \& Somoray, K. (2019). Safety citizenship behavior: A complementary paradigm to improving safety culture within the organizational driving setting. In N. J. Ward, B. Watson, \& K. Fleming-Vogl (Eds.), Traffic safety culture (pp. 145-171). Emerald Publishing. https://doi.org/10.1108/978-1-78714-617420191011

Zabari, M. L., \& Southern, N. L. (2018). Effects of shame and guilt on error reporting among obstetric clinicians. Journal of Obstetric, Gynecologic \& Neonatal Nursing, 47(4), 468-478. https://doi.org/10.1016/j.jogn.2018.03.002

Zohar, D. (1980). Safety climate in industrial organizations: Theoretical and applied implications. Journal of Applied Psychology, 65(1), 96-102. https://doi.org/10.1037/0021-9010.65.1.96

\section{History}

Received October 3, 2020

Revision received August 7, 2021

Accepted August 16, 2021

Published online November 18, 2021

\section{Acknowledgments}

We thank the experts for their participation.

\section{Funding}

Open access publication enabled by Ruhr University Bochum.

\section{ORCID}

Sebastian Sieberichs

(D) https://orcid.org/0000-0002-9338-7325

Annette Kluge

(iDhttps://orcid.org/0000-0002-8123-0427

\section{Sebastian Sieberichs}

Work, Organisational \& Business Psychology

Department of Psychology

Ruhr University Bochum

Universitätsstraße 150

44801 Bochum

Germany

sebastian.sieberichs@rub.de

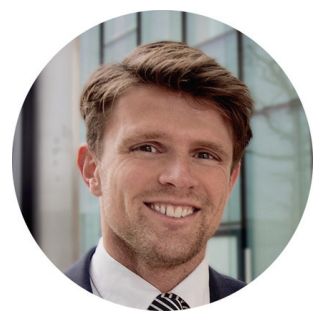

Sebastian Sieberichs is a doctoral candidate at the Department of Industrial and Organizational Psychology at Ruhr University Bochum, Germany. In addition to his work as a commercial pilot for a major European airline, he is employed by the airline's flight safety department. His expertise is in human factors and safety and fatigue management.

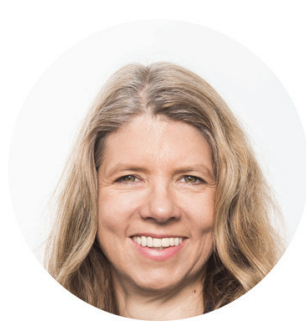

Annette Kluge is Full Professor for Industrial and Organizational Psychology at Ruhr University Bochum, Germany. She obtained her Diploma in $1 / 0$ Psychology at RWTH Aachen and her doctorate in ergonomics and vocational training at the University of Kassel in 1994. Her expertise is in human factors, training science, skill retention, and safety management. 